\title{
Species interactions in an Andean bird-flowering plant network: phenology is more important than abundance or morphology
}

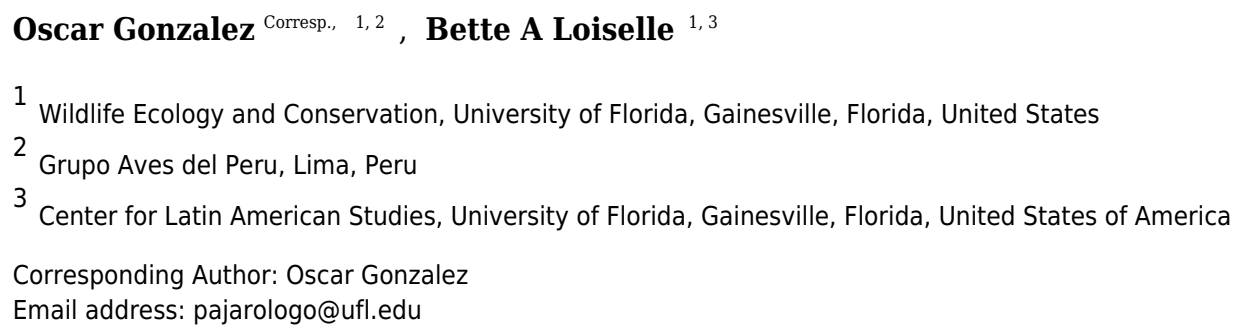

Biological constraints and neutral processes have been proposed to explain the properties of plant-pollinator networks. Using interactions between nectarivorous birds (hummingbirds and flowerpiercers) and flowering plants in high elevation forests (i.e., "elfin" forests) of the Andes, we explore the importance of biological constraints and neutral processes (random interactions) to explain the observed species interactions and network metrics, such as connectance, specialization, nestedness and asymmetry. In cold environments of elfin forests, which are located at the top of the tropical montane forest zone, many plants are adapted for pollination by birds, making this an ideal system to study plant-pollinator networks. To build the network of interactions between birds and plants, we used direct field observations. We measured abundance of birds using mist-nets and flower abundance using transects, and phenology by scoring presence of birds and flowers over time. We compared the length of birds' bills to flower length to identify "forbidden interactions" - those interactions that could not result in legitimate floral visits based on mis-match in morphology. Diglossa flowerpiercers, which are characterized as "illegitimate" flower visitors, were relatively abundant. We found that the elfin forest network was nested with phenology being the factor that best explained interaction frequencies and nestedness, providing support for biological constraints hypothesis. We did not find morphological constraints to be important in explaining observed interaction frequencies and network metrics. Other network metrics (connectance, evenness and asymmetry), however, were better predicted by abundance (neutral process) models. Flowerpiercers, which cut holes and access flowers at their base and, consequently, facilitate nectar access for other hummingbirds, explain why morphological mis-matches were relatively unimportant in this system. Future work should focus on how changes in abundance and phenology, likely results of climate change and habitat fragmentation, and 
the role of nectar robbers impact ecological and evolutionary dynamics of plant-pollinator (or flower-visitor) interactions. 
1 Species interactions in an Andean bird-flowering plant network: phenology is more

2 important than abundance or morphology

3

4 Oscar Gonzalez ${ }^{1,2}$ and Bette A. Loiselle ${ }^{1,3}$

51 Department of Wildlife Ecology \& Conservation, 110 Newins-Ziegler Hall. PO Box

6 110430. University of Florida. Gainesville, FL 32611-0430 USA

$7 \quad$ 2Grupo Aves del Peru. Gomez del Carpio 135, Surquillo. Lima 34, Peru

$8{ }^{3}$ Center for Latin American Studies. 319 Grinter Hall. PO Box 115530. University of

9 Florida. Gainesville, FL 32611-5530 USA

10 Corresponding author:

11 Oscar Gonzalez ${ }^{1,2}$

12 Email address: pajarologo@ufl.edu 
14

\section{Abstract}

Biological constraints and neutral processes have been proposed to explain the properties of plant-pollinator networks. Using interactions between nectarivorous birds (hummingbirds and flowerpiercers) and flowering plants in high elevation forests (i.e., "elfin" forests) of the Andes, we explore the importance of biological constraints and neutral processes (random interactions) to explain the observed species interactions and network metrics, such as connectance, specialization, nestedness and asymmetry. In cold environments of elfin forests, which are located at the top of the tropical montane forest zone, many plants are adapted for pollination by birds, making this an ideal system to study plant-pollinator networks. To build the network of interactions between birds and plants, we used direct field observations. We measured abundance of birds using mist-nets and flower abundance using transects, and phenology by scoring presence of birds and flowers over time. We compared the length of birds' bills to flower length to identify "forbidden interactions" - those interactions that could not result in legitimate floral visits based on mis-match in morphology. Diglossa flowerpiercers, which are characterized as "illegitimate" flower visitors, were relatively abundant. We found that the elfin forest network was nested with phenology being the factor that best explained interaction frequencies and nestedness, providing support for biological constraints hypothesis. We did not find morphological constraints to be important in explaining observed interaction frequencies and network metrics. Other network metrics (connectance, evenness and asymmetry), however, were better predicted by abundance (neutral process) models. Flowerpiercers, which cut holes and access flowers at their base and, consequently, facilitate nectar access for other 
37 hummingbirds, explain why morphological mis-matches were relatively unimportant in

38 this system. Future work should focus on how changes in abundance and phenology, likely results of climate change and habitat fragmentation, and the role of nectar robbers

40 impact ecological and evolutionary dynamics of plant-pollinator (or flower-visitor)

41 interactions.

\section{Introduction}

Interactions between flowering plants and their animal visitors are frequently focused on mutualistic encounters (Bascompte \& Jordano, 2014). In these mutualisms, plants provide food resources (i.e., pollen, nectar), while animals provide pollinator services. Yet, these interactions are not always mutualistic. For example, animals may visit flowers and fail to effectively transfer pollen, as in the case of "nectar-robbers", which bypass reproductive parts of the flower via cutting a hole at the base to access nectar resources (Rojas-Nossa, 2013, Maruyama et al., 2015, Rojas-Nossa, Sanchez \& Navarro, 2016). The presence of nectar-robbers in a system can change the dynamics and structure of plant-flower visitor networks. In these systems, the number and diversity of flower visitors to certain floral resources may increase as more visitors gain access to nectar, although the effectiveness of pollination may remain the same or even decline.

Plant-pollinator (or plant-flower visitor) networks have been relatively well-studied in recent years (Lewinsohn et al., 2006, Burkle \& Alarcon 2011, Dalsgaard et al., 2011, Bascompte \& Jordano, 2014). These networks are almost always characterized by many fewer interactions than are possible and asymmetries (e.g., Jordano, Bascompte \& Olesen, 2003, Vázquez \& Aizen, 2004). Mutualistic networks, such as plant-pollinator 
60

61

62

63

64

65

66

67

68

networks and plant-frugivore networks, often tend towards a nested structure. In the case of a bipartite network, nestedness is higher where more specialist species of one level interact with a few species in the other level, and this subset of species with few links are then shared with more generalist species; (Bascompte et al., 2003, Vázquez and Aizen, 2006, Bascompte, 2010, Thébault \& Fontaine, 2010). Mutualistic networks also have been found to be compartmentalized or modular with groups of species well connected to each other, but less connected to others in the network, usually when they have a large number of species (e.g. Olesen et al., 2007).

Recent research suggests that how networks are structured may influence their stability and co-evolutionary dynamics (Bascompte \& Jordano, 2007, Ebeling, Klein \& Tscarntke, 2011, Allesina \& Tang, 2012, Nuismer, Jordano \& Bascompte, 2013, Suweis et al., 2013, James et al., 2015). Thus, understanding which factors explain the observed interactions and structural properties of the network are key to predicting sensitivity of networks to perturbations, such as loss of species or changes in environmental conditions. Species extinction can be preceded by the extinction of species interactions, so this study contributes to show how network theory can help to explain the web of life in an ecosystem (Bascompte \& Jordano, 2014). In recent years, new analytical approaches have facilitated asking questions about the processes that drive network properties (Vázquez, Chacoff \& Cagnolo, 2009, Encinas-Viso, Revilla \& Etienne, 2012, Winfree et al., 2014, Vizentin-Bugoni, Maruyama \& Sazima, 2014, Olito \& Fox, 2015). Two main hypotheses - neutrality and biological constraints - have emerged in these network studies. The neutrality hypothesis suggests that random interactions among species best explain network structure, such that relative species 
83

84

85

86

87

abundances predict interaction frequencies and can explain resultant structural properties (Vazquez \& Aizen, 2004). In contrast, the biological constraints hypothesis suggests that interactions are shaped by species' traits or phenological patterns (Jordano, Bascompte \& Olesen, 2003, Vazquez, Chacoff \& Cagnolo, 2009, Olesen et al., 2011). In the former, trait mismatches can result in "forbidden interactions" that impede or prohibit interactions among network members, such as when the length or width of the flower opening prohibits animal access to the nectar resources (Jordano, Bascompte \& Olesen, 2003, Olesen et al., 2011). In the latter, phenological mismatches occur when animal presence in an area does not overlap the time when specific plants are flowering (Vazquez, Chacoff \& Cagnolo, 2009).

Support for the neutral or biological constraints hypotheses have been mixed (e.g., see Olito \& Fox, 2015). While information from species relative abundances (neutrality) and phenology (biological constraints) predicted components of network structure in plantpollinator networks from Argentinean shrub land (connectance, nestedness, evenness and interaction asymmetry), neither of these hypotheses explained the observed frequencies of species interactions (Vázquez, Chacoff \& Cagnolo, 2009). In contrast, in a hummingbird-flowering plant network, forbidden interactions from phenological or morphological mismatches were found to drive frequencies of observed interactions (Maglianesi et al., 2014, Maruyama et al., 2014, Vizentin-Bugoni, Maruyama \& Sazima, 2014), although they were not important predictors of network structure (e.g. nestedness, connectance, specialization, evenness and asymmetry; see Maglianesi et al., 2014, Vizentin-Bugoni, Maruyama \& Sazima, 2014). Similarly, phenological mismatches, in combination with relative abundances of network members, played a 
106 role in explaining interaction frequencies between nectarivorous sunbirds and flowering

107 plants (Janecek et al., 2012).

108 Here, we extend these studies to investigate the drivers of species' interactions and 109 network structure in a bird-flowering plant network in "elfin" forests located within the

110 high Andes of Peru (Brack \& Mendiola, 2000). Elfin forests, like other highland sites, are

111 characterized by flowering plants adapted largely for bird pollination, as cold

112 temperatures and often wet conditions limit insect abundance and activity (Dalsgaard et

113 al., 2009, Lloyd et al., 2012). In mainland Americas these forests, while dominated by

114 hummingbirds of various sizes and bill morphologies, also are frequented by Diglossa

115 flowerpiercers (Ramirez et al., 2007). Flowerpiercers feed extensively on nectar, but

116 may offer limited pollinator services as they frequently access flowers via holes they cut

117 at the base of the corolla using their modified beaks (Rojas-Nossa, 2013). Their

118 presence in the system may lessen the importance of morphological constraints in

119 shaping interactions and structural properties of the network as they create

120 opportunities for short-billed hummingbirds to also access flowers with long corollas.

121 Thus, elfin forest networks may not fit the patterns reported earlier where interaction

122 frequencies of networks are predicted by morphology of network members (Maruyama

123 et al. 2014, Vizentin-Bugoni, Maruyama \& Sazima, 2014, Vizentin-Bugoni et al., 2016).

124 By combining information on flower visits, flower phenology, bird (hummingbirds and 125 flowerpiercers) and plant abundance, we address the following questions: 1) How are 126 bird-flowering plant networks of elfin forest structured?, 2) Are observed interaction

127 frequencies and network structural properties driven by biological constraints 128 (morphological and/or phenological mismatches) or neutral processes (i.e., species 
129 relative abundance)?, and 3) How do visits by birds that offer little to no pollinator

130 services affect network properties?

131 Methods

132 Study Area

133 Our study was conducted in the high elevation Andean forests of Peru known as "elfin

134 forest" in Unchog, Huanuco Department, within the Carpish Mountains ( $9^{\circ} 42^{\prime} 32.33^{\prime \prime} \mathrm{S}$,

$13576^{\circ} 9^{\prime} 39.13^{\prime \prime}$ W; 3700 m.a.s.l.). The elfin forest of Unchog is located within the transition

136 between cloud forest and puna grassland. The area is characterized by a dry (May-

137 September; < $150 \mathrm{~mm}$ rain/month) and wet (October-March, $>200 \mathrm{~mm}$ rain/month)

138 season (Supplementary material Fig. A1). The study area is known to harbor a number

139 of endemic bird (Parker \& O'Neill, 1976, Young et al., 2009) and plant species (Beltran

140 \& Salinas, 2010).

141 Within the Unchog area, we sampled birds and plants in three elfin forest sites that had

142 continuous vegetative cover and were $\sim 8$ ha each - Unchog, Magma and

143 Simeompampa; sites were from 0.6 to $1.7 \mathrm{~km}$ apart from each other and intervening

144 habitat between these elfin forest patches was dominated by pasture and shrub land.

145 To explore similarity between sites, we calculated pairwise Sorenson dissimilarity

146 indices for plant species observed in the three sites (see Trojelsgaard et al., 2015)

147 where values close to 0 indicate very similar community composition and values close

148 to 1 indicate very distinct communities. For our sites, Sorenson values ranged from 0.13

149 to 0.25 , indicating very similar plant composition. Further, the flower-visiting bird

150 communities were also very similar. Therefore, sites were combined for network

151 analysis due to the overlap in plant and bird species and the likely non-independence of 
152 the sites. This combination of sites increased power to characterize network with

153 increased sample size.

154 This research was conducted under permits of the Peruvian government, Resolucion

155 151-2014-MINAGRI-DGFFS-DGEFFS and Resolucion 182-2012-AG- DGFFS-DGEFFS

156 and the approval of the Institutional Animal Care \& Use Committee of the University of

157 Florida; IACUC Study \#201105714.

158 Behavioral Observations

159 We quantified the flowering plant-bird network with direct observations on birds and

160 plants using transects and focal plant watches (Ortiz-Pulido et al., 2012). These

161 observations occurred between May 2011 and August 2014. Bird-plant interactions

162 were observed using transects in the elfin forest patches approximately weekly during

163 May-July 2011, February 2012, July-November 2012, January-July 2013, September

164 2013, and November 2013. During these visits, one of us (OG) walked along set

165 transects inside the forest and along forest edges observing birds and recording which

166 plants and how many flowering plants they visited during visits to the sites. If the bird

167 visited more than one flower on a given plant during a visit, this was still scored as a

168 single visit. In January 2014 and from May-August 2014 we recorded all visits to the

169 flowering plants visited by birds using focal plant watches during 30-minute blocks.

170 During these 30 minute observation periods, multiple individual plants and plant species

171 were simultaneously observed. Focal plant observations were centered on plant species

172 exhibiting typical floral traits found in bird pollination syndrome (Willmer, 2011), and

173 those that were known or suspected to be visited by birds based on previous

174 observations (e.g., see Maruyama et al., 2013). We distributed these observations

175 among the sampling areas in points at least $100 \mathrm{~m}$. apart. The time of observation for 
176 each species was proportional to the abundance of the plant species. The combined

177 observations of birds from transects and focal plants were used to build the interaction

178 network (Walther \& Brieschke, 2001).

179 We spent a total of 190 hours (150 h in dry and $40 \mathrm{~h}$ in wet season) observing

180 interactions over 79 days; 73 h, 52 h, and 65 h in Unchog, Magma, and Simiumpampa, 181 respectively. This effort was divided between transects (79\%) and focal plant watches

182 (21\%); $50.7 \%$ and $49.3 \%$ of observed interactions were recorded by transects and focal 183 plant watches, respectively. More time was spent during the dry season both because 184 of increased flower abundance as well as logistics of working in the area.

185

186

188

189

190

191

192

193

194

195

196

197

198

\section{Plant Phenology and Abundance}

We used transects to record abundance and phenology of flowers in the three sampling sites. We set up one transect per study site; these transects were sampled once a month at times when behavioral observations occurred. The presence or absence of flowers on a monthly basis was used to characterize phenology for each plant species. We counted the numbers of flowers per individual plant, or estimated the number of flowers by counting a subsample of flowers and then extrapolated to the whole plant for plants with $>50$ flowers. We converted the number of flowers to flowers per ha based on area sampled; in some transects, we corrected for effective area sampled given steep topography and inability to sample some areas at a $20 \mathrm{~m}$ width. We used flower density as a measure of plant relative abundance, as it has been shown to be a better estimator than the density of individual plants due to the high variability of flowers per plant (Vázquez, Chacoff \& Cagnolo, 2009). For this network analysis, data were combined across sites and years due to similarities in species composition among sites 
199 and because sample sizes did not warrant more detailed examination of spatial and

200 temporal patterns.

201 Nectarivorous Bird Phenology and Abundance

202 To determine the phenology of birds at sites on a monthly basis, we scored presence or

203 absence of birds based on point-counts, ad-hoc and behavioral observations, and mist-

204 netting activities. To estimate overall relative abundance of bird species, we relied on

205 mist-netting activities. We used 10-15 mist-nets ( $6 \mathrm{~m}$ or $12 \mathrm{~m}$ length, $36 \mathrm{~mm}$ mesh) by

206 sampling bout in all the sites to capture birds, collect pollen when present from bills for

207 further studies, and measure bill length and other morphological characters. Nets were

208 distributed along forest edge and within the forest interior; nets were opened on one day

209 per month overlapping periods where behavioral observations or focal plant watches

210 occurred. Over the course of the study, mist-nets were opened a total of 2399 mist-net

211 hours (one 12-m net open 1 hour = 1 mist-net hour). Vegetation height in the study area

212 is $5 \mathrm{~m}$ on average and, thus, most birds that use the forest are expected to be captured

213 using mist-nets. We recognize that not all birds are equally captured by mist-nets (e.g.

214 Remsen \& Good, 1996), and thus estimates may be biased. Nonetheless, in montane

215 forest mist-netting is widely used as a recommended method for bird assessment (Lloyd

216 et al., 2012, Maglianesi et al., 2014). As for plants, we combined the results among sites

217 to characterize the bird community and bird-flower observations.

218 Morphological Measurements

219 We measured bill length and width (to nearest $0.1 \mathrm{~mm}$ ) of birds that visited flowers

220 using individuals captured in mist nets, supplemented by measurements from museums

221 and published literature. We measured an average of 25 specimens per bird species.

222 Since hummingbirds extend their tongues to access nectar inside the flowers, we added 
$2231 / 3$ rd of the total length of the bird bill following Vizentin-Bugoni, Maruyama \& Sazima

224 (2014); in a later paper Vizentin-Bugoni et al. (2016) recommend using a 80\% tongue

225

226

227

228

229

230

231

232

233

234

235

236

237

238

239

240

241

242

243

244

245

246

extension to correct bill measurement, although they found no difference in results when either $33 \%$ or $80 \%$ is used. We measured the length and the width (to nearest $0.1 \mathrm{~mm}$ )

of flower corollas for plants visited by birds in the field, supplemented by measurements from herbarium specimens. The length was measured from the flower opening to the base of the nectar chamber, while the width was measured at the flower's widest aperture.

\section{Network Description}

Data on observed interactions at flowers were recorded as matrices with the bird flower visitors in columns, the plant species in rows and cell values representing the number of visits following Jordano, Vázquez \& Bascompte (2009) and Bascompte \& Jordano (2014). We examined sampling completeness of nectarivorous birds and interactions in the study area using the Chao2 estimator in EstimateS version 9.1 (Colwell, 2013) following Chacoff et al. (2012). See Supplementary material Fig. A2.

We calculated the following network metrics: connectance, nestedness, interaction evenness and interaction asymmetry (Bascompte \& Jordano, 2014). We also calculated a specialization index at the network level (H2') which is resilient to sample size and network size (Blüthgen, Menzel \& Blüthgen, 2006). Connectance, which varies from 0 to 1 , is the realized proportion of possible links in the network (i.e., if every bird visited flowers of every plant species, then connectance would equal 1). Nestedness provides a measure of the aggregation of the distribution of interactions in the network (Nielsen \& Bascompte, 2007). To calculate nestedness, we used a weighted nestedness measure (WNODF) because WNODF has been found to be more robust in quantitative networks 
247 (Almeida-Neto \& Ulrich, 2011). When WNODF is close to 0 there is no evidence of

248 aggregation in the matrix, whereas as it approaches 100 , the interactions are

249 increasingly nested. Interaction evenness is based on Shannon's index following

250 Tylianakis, Tscharntke \& Lewis (2007) and provides a measure of the distribution of

251 interactions in the network. High skewness in the distribution of interactions is indicative

252 of an uneven network. Interaction asymmetry, which measures the strength and

253 directionality of the interaction of one level to the other (birds and plants in this case),

254 was calculated for plants and for birds separately; higher absolute values, from - 1 to 1

255 indicate more uneven or skewed distribution of interaction frequencies. $\mathrm{H} 2$ ' measures

256 specialization in the matrix based on the $\mathrm{H}$ index of Shannon-Wiener (Blüthgen, Menzel

257 \& Blüthgen, 2006). H2' describes how much the observed distribution of species

258 interactions deviate from the frequency of the expected distribution. It ranges from 0 to

2591 ; when $\mathrm{H} 2$ ' is closer to 1 , the interactions are considered to reflect a high degree of

260 specialization. Connectance (conn), nestedness (WNODF), evenness (interaction

261 evenness), specialization (H2'), and interaction asymmetry (intrasymm) were calculated

262 using bipartite package version 2.05 in R (Dormann, Gruber \& Fründ, 2008). See

263 Supplementary material Table A1 for R source code.

264 Interaction Probability Matrices

265 We built interaction probability matrices using the framework proposed by Vázquez,

266 Chacoff \& Cagnolo (2009) where interaction frequencies were assumed to be

267 determined by relative abundances, temporal (phenological) overlap, and morphological

268 overlap. As above, these probability matrices are based on the data compiled across

269 the three study sites. Relative abundance probability matrices will provide a test of the

270 neutrality hypothesis, while the latter two (phenology, morphology) provide a test of the 
271 biological constraints hypothesis in explaining observed network structure and

272 interaction frequencies.

273 To develop a phenological interaction probability matrix (PhenMat), we first compiled

274 matrices of temporal overlap for plants and birds. In these matrices, plant or bird

275 species were rows and sampling months were columns with ones and zeros for

276 presence and absence; the total number of months with simultaneous data on both

277 plants and birds were 15. We then used matrix multiplication to obtain temporal overlap

278 between birds and plants. This matrix of temporal overlap was normalized such that the

279 matrix cells added up to a total of one; individual cells with higher values indicated

280 greater temporal overlap, or probability of interaction, of any particular bird-plant pair.

281 An abundance interaction probability matrix (AbMat) was made in a similar way as the

282 phenological matrix, compiling matrices of abundance for plants and for birds and

283 overlapping them in the same months. Here the cells of the plant matrix were the

284 number of individual flowers per ha, by species summed across the sites. The cells of

285 the bird matrix were the number of individuals captured in mist-nets per 100 net-hours

286 (Maglianesi et al., 2014). We multiplied the two abundance matrices and the product

287 was normalized as explained above.

288 The morphology interaction probability matrix (MorMat) was generated to account for 289 morphological mismatches in length of a bird's bill (as corrected to account for tongue, 290 see above) and corolla length (Maruyama et al., 2014; Vizentin-Bugoni, Maruyama \&

291 Sazima, 2014). However, instead of using mean length, we used the probability of size

292 overlap between ranges of flower length and bill length. We believe this approach is

293 more realistic than a simple yes or no criterion because of existing intra-specific 
294 variation in morphological traits among individuals (Gonzalez-Castro et al., 2015,

295 Gonzalez-Varo \& Traveset, 2016). We first noted the range of a flower's length and the

296

297

298

299

300

301

302

303

304

305

306

307

308

309

310

311

312

313

314

315

316 range of a bird's bill. If the lower limit of the bill's range was longer than the lower limit of the flower's length, the interaction was scored as $100 \%$ possible with a cell value of 1 . If the upper limit of the bill's range was shorter than the lower limit of the flower's length, the interaction was considered impossible and a cell value of 0 was assigned. When there was overlap of ranges between the length of a bird's bill and the length of a corolla, we calculated the proportion of overlap and assigned that value to the cell. Furthermore, we considered some exceptions when the flower's width was expansive enough for a bird's head to enter the corolla. For example, the flowers of Puya are longer and wider than any of the bird's bills, so we considered that all bird species could visit Puya and assigned a value of 1 for all possible interations with this flowering species. In cases where size overlap was zero, but the observed interaction frequency was not zero, we assigned an arbitrary value of $1 \times 10^{-8}$ which is less probable than any other case in the phenology and abundance matrices (Gonzalez-Castro et al., 2015). Further, the placement of zero in the probability matrix when the observed interaction value is not zero, results in a failed calculation of the multinomial function (see next topic). As for other interaction probability matrices, we normalized this matrix so that cell values sum to 1.

We also considered the possibility that factors might act together to influence the observed bird-flower network. To do this, we used matrix multiplication to create new interaction probability matrices for all possible combinations - AbMat*PhenMat, AbMat*MorMat, PhenMat*MorMat and AbMat*PhenMat*MorMat - and then normalized 
317 these new matricies so that the cells summed to one. Following Vázquez, Chacoff \&

318 Cagnolo (2009) we also included a "Null" probability matrix where all pairwise

319 interactions in the matrix made of observed plant and animal species had the same

320 probability of occurrence (i.e., all cell values in the matrix are equal to $1 / \mathrm{IJ}$, where $I$ and

$321 J$ are number of plant and bird species in the network).

322 Testing Neutrality and Biological Constraints Hypotheses

323 To test whether neutral processes or biological constraints best predicted observed

324 interaction frequencies, we used a likelihood approach. Support for either of these

325 hypotheses arises when the probability matrix can predict the observed interactions,

326 such that higher probabilities of cells should match with higher frequencies of observed

327 interactions (see Vázquez, Chacoff \& Cagnolo, 2009, Vizentin-Bugoni, Maruyama \&

328 Sazima, 2014). Akaike information criteria (AIC) was used to compare the relative ability

329 of these various hypothesized models to explain observed interactions. We assumed

330 that probability of interaction between a given bird and flowering plant followed a

331 multinomial distribution (Vázquez, Chacoff \& Cagnolo, 2009). We used the number of

332 species (44 in total), to determine the number of parameters used to weight different

333 models' complexities when calculating AIC. So 44 was used when one factor was

334 calculated (i.e. abundance), 88 if two factors (i.e. phenology and morphology) and 132 if

335 three factors (i.e. phenology, morphology and abundance). As in Vizentin-Bugoni,

336 Maruyama \& Sazima (2014) we compared these results to those based on using the

337 number of factors (abundance, phenology, morphology; either. e., 1, 2 or 3) to weight

338 model complexity, and checked for differences. The function dmultinomin in the stats

339 package $\mathrm{R}$ was used to calculate likelihood ( $\mathrm{R}$ core team 2014). 
340 To determine the degree to which the hypotheses predicted network metrics, such as

341 connectance, nestedness, or asymmetry, we used a randomization algorithm mgen

342 from bipartite package in R (Vázquez, Chacoff \& Cagnolo, 2009). Using the number of

343 interactions actually observed, the randomization algorithm assigned interactions to

344 each probability interaction matrix, including all combined interaction probability

345 matrices, such that all species received at least one interaction (see Vázquez, Chacoff

346 \& Cagnolo, 2009). From these randomized matrices, we calculated network statistics

347 (mean and 95\% confidence intervals from 1000 repetitions using function confint in

348 bipartite package in R) and compared the overlap with network statistics generated from

349 our observed interaction matrix. If the observed metric values were found to be within

350 the $95 \%$ confidence intervals of those generated from interaction probability matricies,

351 we interpreted this to mean that factors (e.g., relative abundance, phenology,

352 morphology, or their combination) could explain or were consistent with hypothesized

353 explanations of drivers of mutualistic interactions at the community level.

\section{Effect of Nectar-robbers on Network Properties}

355 To examine the influence of nectar robbers on network properties, we recalculated all of

356 the above matrices after removing interactions that likely did not result in pollination,

357 such as visits to base of flowers through holes cut by Diglossa flowerpiercers or bees.

358 This new interaction matrix is more equivalent to a pollinator-plant network than our

359 bird-flowering plant network which included all flowering plant visits (Maruyama et al.,

360 2015). This pollinator-plant network was then used to evaluate our third question that

361 examined the impact of flowerpiercers on network structure and network properties as

362 described above 


\section{Results}

\section{General Results}

365 Bird-flower network. We observed a total of 17 bird species visiting flowers from 27

366 plant species in all our elfin forest sites combined. These observations included 278

367 pairwise interactions representing 74 unique interactions of bird visits to plants

368 (Supplementary Table A2). Avian flower visitors included 12 species of hummingbirds

369 (Trochilidae), 4 species of flowerpiercers (Diglossa: Thraupidae) and one conebill

370 (Conirostrum: Thraupidae). Flowering plants observed to be visited by birds included

371 plants from 24 genera, 16 families and 14 orders (Fig. 1, and Supplementary Table A3).

372 Mutualistic networks are typically characterized by many fewer observed interactions

373 than possible (e.g., Chacoff et al., 2012), and this was also true here. We detected only

$37455.2 \%$ of the estimated interactions for the whole network using Chao2 (Supplementary

375 material Fig. A2). Despite this, the observed number of unique interactions appeared to

376 be reaching an asymptote with our sampling effort.

377 Interactions in the network. We found that Metallura theresiae, Pterophanes

378 cyanopterus and Diglossa mystacalis, birds considered to be indicators of the elfin

379 forest (Parker, Stotz \& Fitzpatrick, 1996), were the most important bird species in terms

380 of flowering plant interactions (Fig. 1). Metallura visited a total of 26 species, while $D$.

381 mystacalis visited 10 and Pterophanes visited 4 species, respectively. Among plants,

382 Brachyotum lutescens, Tristerix longebracteatus and Fuchsia decussata were the

383 species with the most interactions with visits from 8,7 , and 7 bird species, respectively

384 (Fig. 1). When compared to the "null" model, the bird-flowering plant network was found

385 to be significantly less connected and more nested (Figs. 2a, b). In addition, the network 
386

387

388

389

390

391

392

393

394

395

396

397

398

399

400

401

402

403

404

405

406

407

408

409

was significantly less even, more specialized and exhibited greater asymmetry among

bird or plant species than expected (Figs. 2c-f).

\section{Plant-visitation network determinants}

We found that biological constraints as exemplified by phenology best explained the observed interaction frequencies using the likelihood approach (Table 1). This result suggests that the degree of temporal overlap among interacting players in a birdflowering plant network is an important driver of the observed interaction frequencies.

Results were consistent whether either the number of species or the number of matrices used as parameters in likelihood analysis to compare among models (Supplementary material Fig. A3).

Biological constraints, either through phenological constraints or phenology in combination with morphology, were found to explain nestedness in the elfin forest birdplant network (Fig. 2b). Network structure also was found to be explained by neutral processes, as measured by relative abundance of birds and flowering plants, in some cases. For example, connectance within the network was predicted via a combination of relative abundance of interacting players and biological constraints (Fig. 2a). Further, relative abundance was found to explain evenness and relative abundance alone, or in combination with morphology, explained asymmetry (Fig. 2e, 2f). In contrast, neither biological constraints nor neutral processes were able to explain specialization (Fig. 2d).

\section{Difference in network properties with and without nectar-robbers}

To investigate the influence of nectar robbers in the plant-bird network, we removed all interactions that involved observed 'illegitimate" visits to flowers (i.e., birds entered flower at the base rather than through the corolla opening). This reduced the original network of 17 birds and 27 plants to 12 birds and 26 plants; all Diglossa species 
410 dropped out of the network given that all observations were from Diglossa or

411 Conirostrum removing nectar from the base of flowers. Other interactions deleted were

412 Heliangelis amestyticollis - Desfontainia spinosa, Pterophanes cyanopterus - Passiflora

413 cumbalensis, Metallura tyrianthina - Passiflora cumbalensis and Metallura theresiae

414 with Desfontainia spinosa, Fuchsia decussata and Passiflora cumbalensis. Removal

415 resulted in the loss of all interactions with Passiflora cumbalensis, given that all

416 observations to this flower occurred via the floral base and were not considered

417 "legitimate".

418 The exclusion of illegitimate visits by primary and secondary nectar-robber birds

419 resulted in a decrease of connectance, nestedness and evenness, but increase in

420 specialization when comparing metrics with the null matrix and the original matrix.

421 Asymmetry shifted in different ways with an increase for plants and decrease for birds

422 (compare Figs. 2 and 3). Abundance and its combination with morphology were useful

423 to explain evenness and asymmetry for plant and birds, while phenology in combination

424 with morphology predicted connectance. However the exclusion of the nectar-robbers in

425 the network did not change the influence of phenology as the "best" predictor of species

426 interactions (Table 1).

\section{Discussion}

\section{Network Structure}

429 We found that bird-flowering plant networks in the elfin forests studied here are characterized by fewer interactions than those possible. These results are consistent

431 with most other pollination networks studied (Bascompte \& Jordano, 2014). As a

432 coincidence, Chacoff et al. (2012) also observed about 55\% of all possible interactions 433 in a desert plant-pollinator network sampled over 4 years. Yet, despite their time 
434 investment, Chacoff et al. (2012) estimate that a five-fold increase in sample effort

435 would be needed to even possibly detect $90 \%$ of the possible interactions. The

436

437

438

439

440

441

442

443

444

445

446

447

448

449

450

451

452

453

454

455

456

sampling effort invested in our study (190 hours) spread over multiple years matches or exceeds many other studies in bird-flowering plant networks (e.g., Rodriguez-Flores, Stiles \& Arizmendi, 2012, Ortiz-Pulido et al., 2012, Maruyama et al., 2014), but is considerably less than Traveset et al. (2015) and studies that use video-cameras to record interactions (Maglianesi et al., 2014, Vizentin-Bugoni, Maruyama \& Sazima, 2014, Vinzentin-Bugoni et al., 2016). The use of remote technology in flowering plant observational studies hold much promise, but are nonetheless, difficult or expensive to use in sites where flowering plant diversity is high.

Like several mutualistic networks, the elfin forest network was also found to be nested (Fig.3b; see also Rodriguez-Flores, Stiles \& Arizmendi, 2012, Bascompte et al., 2003). Our results, however, contrast with some studies in tropical dry forests (Arizmendi \& Ornelas, 1990) and Atlantic forests (Vizentin-Bugoni, Maruyama \& Sazima, 2014) where the plant-bird network was not nested using the same qualitative metric (WNODF). However in a more recent analysis an updated version of this Atlantic forest network was nested using a binary measure (Vinzentin-Bugoni et al., 2016). Bascompte et al. (2003) suggest that increases in the number of species in networks might result in greater nestedness. Sebastian-Gonzalez et al. (2015) confirmed this increase in nestedness with greater number of species, but other studies found no such effect (Cuartas-Hernandez \& Medel, 2015) or even reduced nestedness with increased number of species (Ramos-Robles et al., 2016). Indeed, when we reduced the network to only include species and observations that resulted in "legitimate" flower visits, we 
457 found nestedness values were lower although the network was still more nested than

458 expected. In the elfin forest the abundance of the flowerpiercers facilitating access to

459 hummingbirds would take out several "forbidden links" as limitations, diminishing

460 nestedness. Sampling effort did not likely bias our estimate of nestedness given that

461 WNODF is known to be a robust estimator for nestedness in nectarivore bird-plant

462 networks (Vizentin-Bugoni et al., 2016, but see Costa et al., 2016).

463 The important species in networks, based on their abundance and frequency of

464 interactions, often provide insights about the ecological or evolutionary implications of

465 the network (Bascompte \& Jordano, 2007). In this system the most abundant flower

466 visitor in elfin forests (Metallura theresiae) also had the greatest number of connections

467 and interacted with the most flowering plant species (Fig. 1). Metallura theresiae is quite

468 aggressive and its behavior may interfere with other flower visitors, and thus, may affect

469 visitation rates (Justino, Maruyama \& Oliveira, 2012). In contrast, the plant which had

470 the greatest number of flowers in this system, Brachyotum lutescens, did not have the

471 greatest number of flower visits nor the greatest number of visiting species. Similar

472 results were reported by Rodriguez-Flores, Stiles \& Arizmendi (2012) in a plant-

473 hummingbird network in Colombia, where hermit hummingbirds were the most

474 abundant birds, visiting the greatest number of plant species in the lowland Amazon.

475 In the elfin forest system we found that abundance models combined with phenology or

476 morphology can explain network connectance, as well as evenness and asymmetry for

477 both plants and birds. Nestedness was predicted by phenology and phenology with

478 morphology, matching results from an insect-plant network in a subalpine community

479 (Olito \& Fox, 2015). In contrast, in plant-hummingbird networks in the Brazilian Atlantic 
480 forest (Vizentin-Bugoni, Maruyama \& Sazima, 2014) neither abundance, morphology

481 nor phenology were associated with network metrics, except the mixed model of

482 phenology, morphology and abundance for the asymmetry of the birds in the network.

483 Observed interaction frequencies

484 In this study, the observed interactions, either with the full suite of avian flower visitors 485 or the reduced set of "legitimate" visitors, were best explained by phenology. Greater 486 phenological overlap in birds and plants led to greater number of interactions between 487 pairs of species. The importance of phenology in explaining pairwise interactions has 488 also been found in other studies, but was still found to be a poor predictor of observed 489 interactions in some cases (Encinas-Viso, Revilla \& Etienne, 2012, Olito \& Fox, 2015). 490 In contrast, morphology alone, or morphology interacting with phenology, have been 491 found to explain observed pairwise interactions in some hummingbird-plant networks 492 (Maglianesi et al., 2014, Maruyama et al., 2014, Vizentin-Bugoni, Maruyama \& Sazima, 493 2014). The importance of phenology in driving interactions highlight the potential vulnerabilities of these mutualism networks to climate change, which can alter phenological patterns (Dalsgaard et al, 2011, Rafferty, CaraDonna \& Bronstein, 2015). particularly impacted by climate change and, thus, as phenological patterns change, nectarivorous birds, a number of which are endemic, may face lowered availability of resources and potential invasion of competitors (Sekercioglu, Primack \& Wormworth, 500 2012).

\section{The nectar robber effect in the network}


504 result is likely due to the presence of Diglossa flowerpiercers. The opportunities for

505 morphological constraints to operate in this system are many as several flowering plant

506 species have corollas that exceed the length of a number of flower visitors. Yet, the

507 forbidden interactions in this network, which hypothetically should restrict access to

508 nectar for small-billed birds for a number of flowering species, were allowed. Diglossa,

509 which cut holes in base of flowers to gain access to nectar, act as facilitators for other

510 species (hummingbirds with small bills) that would not be able to access to long-corolla

511 flowers (Bruno, Stachowicz \& Bertness, 2003); large bees are also known to cut holes

512 at base of flowers in this system and may also serve as "facilitators". Consequently,

513 connectance in the network increases with flowerpiercers in the system (Fig. 2a with

514 Fig. 3a). In contrast, we found that network specialization increased markedly when

515 nectar-robbers were removed from the network (Fig. 2d with Fig. 3d).

516 In this study several factors might influence our results. First, we observed only about

$51755 \%$ of all possible pairwise interactions. If our system were undersampled, including

518 potentially "missing" interactions due to not capturing flowering events because of

519 limited sampling, we might have been less likely to see biologically constrained

520 interactions, and thus, may have overestimated their effect. However, we did find that

521 the number of observed pairwise interactions appeared to be reaching an asymptote,

522 suggesting we had sufficiently characterized the network. Second, as most

523 observations were based on transects, we might expect that abundance may emerge as

524 a driver of network interactions and properties as abundant species may be sampled

525 more often in focal plant watches. Nevertheless, the amount of interactions detected by

526 transects was almost the same as the interactions detected by focal watch. The 
527 importance of relative abundance as a driver, however, did not play a large role in

528 explaining observed interactions when compared to other factors. Third, we also did not

529 examine the importance of body size of birds and nectar production in explaining

530 network structure. Nectar production can be highly variable both within and among

531 plants and is difficult to adequately measure when dealing with many plant species.

532 Large-bodied birds, in particular, might focus more on plant species that produce more

533 nectar. These factors might be especially important in explaining network properties

534 such as specialization. Further studies would benefit from including additional

535 predictors of networks.

536 In summary, in elfin forests biological processes were important in predicting observed

537 interactions between flowering plants and birds, while neutral and biological processes

538 interacted to explain network components. In particular, the importance of neutral

539 processes (i.e., abundance) was the single best predictor for four of six network metrics

540 in networks with and without illegitimate interactions. However, the importance of

541 phenology for both species interactions and network structure suggests that the

542 ecological and evolutionary dynamics of networks are likely to be altered with climate

543 change. As such, future studies should focus on how phenological changes, as well as

544 changes in abundance impact network dynamics.

545 Acknowledgements

546 We thank Camilo Diaz, Bernie Britto and Juan Diego Shoobridge for plant identification.

547 OG thanks Jessica Burnett and J. Vizentin-Bugoni for their help in R codes.

548 References 
549 Allesina S, Tang S. 2012. Stability criteria for complex ecosystems. Nature 483:205-

550 208. DOI: $10.1038 / 487175 a$

551 Almeida-Neto M, Ulrich W. 2011. A straightforward computational approach for

552 measuring nestedness using quantitative matrices. Environmental Modelling \& Software

$553 \quad 26: 173-178$. DOI:10.1016/j.envsoft.2010.08.003

554 Arizmendi MD, Ornelas JF. 1990. Hummingbirds and their floral resources in a tropical

555 dry forest in Mexico. Biotropica 22:172-180. DOI: 10.2307/2388410

556 Bascompte J. 2010. Structure and Dynamics of Ecological Networks. Science 329:765-

557 766. DOI: 10.1126/science. 1194255

558 Bascompte J, Jordano P. 2007. Plant-animal mutualistic networks: The architecture of

559 biodiversity. Annual Review of Ecology and Systematics 38:567-593. DOI:

560 10.1146/annurev.ecolsys.38.091206.095818

561 Bascompte J., Jordano P. 2014. Mutualistic networks. Monographs in Population

562 Biology Series, no. 53. Princeton University Press.

563 Bascompte J, Jordano P, Melian C, Olesen JM. 2003. The nested assembly of plant-

564 animal mutualistic networks. Proceedings of the National Academy of Sciences of the

565 United States of America 100:9383-9387. DOI: 10.1073/pnas.1633576100

566 Beltran H, Salinas I. 2010. The vascular flora and vegetation of the Carpish Humid

567 Montane Forests (Huanuco - Peru). Arnaldoa 17(1): 107 - 130 
568 Blüthgen N, Menzel F, Blüthgen N. 2006. Measuring specialization in species

569 interaction networks. BMC Ecology 6:9. DOI: 10.1186/1472-6785-6-9

570 Brack A, Mendiola C. 2000. Ecologia del Peru. Lima: Bruño.

571 Bruno JF, Stachowicz JJ, Bertness MD. 2003. Inclusion of facilitation into ecological

572 theory. Trends in Ecology and Evolution 18:119-125. DOI: 10.1016/S0169-

$5735347(02) 00045-9$

574 Burkle LA, Alarcon R. 2011. The future of plant-pollinator diversity: understanding 575 interaction networks across time, space, and global change. American Journal of

576 Botany 98:528-538. DOI: 10.3732/ajb.1000391

577 Chacoff NP, Vazquez DP, Lomascolo SB, Stevani EL, Dorado J, Padron B. 2012.

578 Evaluating sampling completeness in a desert plant-pollinator network. Journal of

579 Animal Ecology 81:190-200. DOI: 10.1111/j.1365-2656.2011.01883.x

580 Colwell RK. 2013. EstimateS: Statistical estimation of species richness and shared

581 species from samples. Version 9. Persistent URL <purl.oclc.org.estimates>

582 Costa JM., da Silva LP, Ramos JA, Heleno RH. 2016. Sampling completeness in seed 583 dispersal networks: When enough is enough. Basic and Applied Ecology 17:155-164.

584 DOI: 10.1016/j.baae.2015.09.008

585 Cuartas-Hernandez S, Medel R. 2015. Topology of Plant - Flower-Visitor Networks in a 586 Tropical Mountain Forest: Insights on the Role of Altitudinal and Temporal Variation.

587 PLoS ONE 10(10) e0141804. DOI:10.1371/journal.pone.0141804 
588 Dalsgaard, B., Magård E., Fjeldså J., Martín González A.M., Rahbek C., Olesen J.M., 589 Ollerton J., Alarcón R, Cardoso Araujo A, Cotton PA, Lara C, Machado CG, Sazima I, 590 Sazima M, Timmermann A, Watts S, Sandel B, Sutherland WJ, Svenning JC. 2011.

591 Specialization in plant-hummingbird networks is associated with species richness, 592 contemporary precipitation and quaternary climate-change velocity. PLoS ONE 6, 593 e25891. DOI: http://dx.doi.org/10.1371/journal.pone.0025891

594 Dormann CF, Gruber B, Fründ J. 2008. Introducing the bipartite package: Analysing 595 Ecological Networks. R News 8(2):8-11.

596 Ebeling A, Klein A-M, Tscharntke T. 2011. Plant-flower visitor interaction webs:

597 Temporal stability and pollinator specialization increases along an experimental plant 598 diversity gradient. Basic and Applied Ecology 12:300-309. DOI:

599 10.1016/j.baae.2011.04.005

600 Encinas-Viso T, Revilla A, Etienne R. 2012. Phenology drives mutualistic network 601 structure and diversity. Ecology Letters 15:198-208. DOI: 10.1111/j.1461-

$602 \quad 0248.2011 .01726 . x$

603 Gonzalez-Castro A, Yang S, Nogales M, Carlo TA. 2015. Relative importance of 604 phenotypic trait matching and species' abundances in determining plant-avian seed 605 dispersal interactions in a small insular community. - AoB PLANTS 7. 606 DOI: 10.1093/aobpla/plv017.

607 Gonzalez-Varo J, Traveset A. 2016. The Labile Limits of Forbidden Interactions. Trends 608 in Ecology \& Evolution 31:700-710. DOI: http://dx.doi.org/10.1016/j.tree.2016.06.009 
609 James A, Plank M, Rossberg A, Beecham J, Emmerson M, Pitchford J. 2015.

610 Constructing Random Matrices to Represent Real Ecosystems. American Naturalist

611 185:680-692. DOI: 10.1086/680496

612 Janecek S, Riegert J, Sedlacek O, Bartos M, Horak D, Reif J, Padysakova E, Fainova

613 D, Antczak M, Pesata M, Mikes V, Patacova E, Altman J. 2012. Food selection by avian

614 floral visitors: an important aspect of plant-flower visitor interactions in West Africa.

615 Biological Journal of the Linnean Society 107:355-367. DOI: 10.1111/j.1095-

$616 \quad 8312.2012 .01943 . x$

617 Jordano P, Bascompte J, Olesen JM. 2003. Invariant properties in coevolutionary

618 networks of plant-animal interactions. Ecology Letters 6:69-81. DOI: 10.1046/j.1461-

619 0248.2003.00403.x

620 Jordano P, Vázquez D, Bascompte J. 2009. Redes complejas de interacciones

621 mutualistas planta-animal. in Medel, R, Aizen M \& Zamora R, editors. Ecología y

622 evolución de las interacciones planta-animal: conceptos y aplicaciones. Santiago de

623 Chile: Editorial Universitaria, 17-41.

624 Justino DG, Maruyama PK, Oliveira PE. 2012. Floral resource availability and

625 hummingbird territorial behaviour on a Neotropical savanna shrub. Journal of

626 Ornithology 153:189-197. DOI: 10.1007/s10336-011-0726-x

627 Lewinsohn T, Prado P, Jordano P, Bascompte J, Olesen JM. 2006. Structure in plant-

628 animal interaction assemblages. Oikos 113:174-184. DOI: 10.1111/j.0030-

$629 \quad 1299.2006 .14583 . x$ 
630 Lloyd H, Sevillano Rios S, Marsden SJ, Valdes-Velasquez A. 2012. Bird community

631 composition across an Andean tree-line ecotone. Austral Ecology 37(4):470-478. DOI:

632 10.1111/j.1442-9993.2011.02308.x

633 Maglianesi MA, Blüthgen N, Boehning-Gaese K, Schleuning M. 2014. Morphological 634 traits determine specialization and resource use in plant-hummingbird networks in the 635 neotropics. Ecology 95:3325-3334. DOI: 10.1890/13-2261.1

636 Maruyama PK. Oliveira GM, Ferreira C, Dalsgaard B, Oliveira PE. 2013. Pollination 637 syndromes ignored: importance of non-ornithophilous flowers to Neotropical savanna 638 hummingbirds. Naturwissenschaften 100:1061-1068. DOI: 10.1007/s00114-013-1111-9

Maruyama PK, Vizentin-Bugoni J, Oliveira GM, Oliveira PE, Dalsgaard B. 2014.

640 Morphological and Spatio-Temporal Mismatches Shape a Neotropical Savanna Plant-

641 Hummingbird Network. Biotropica 46:740-747. DOI: 10.1111/btp.12170

642 Maruyama PK., Vizentin-Bugoni J, Dalsgaard B, Sazima I, Sazima M. 2015. Nectar 643 robbery by a hermit hummingbird: Association to floral phenotype and its influence on 644 flowers and network structure. Oecologia 178: 783793.

645 Nielsen A, Bascompte J. 2007. Ecological networks, nestedness and sampling effort. 646 Journal of Ecology 95:1134-1141. DOI: 10.1111/j.1365-2745.2007.01271.x

647 Nuismer SL, Jordano P, Bascompte J. 2013. Coevolution and the architecture of 648 mutualistic networks. Evolution 67:338-354. DOI: 10.1111/j.1558-5646.2012.01801.x 
649 Olesen JM, Bascompte J, Dupont Y, Jordano P. 2007. The modularity of pollination 650 networks. Proceedings of the National Academy of Sciences of the United States of 651 America 104:19891-19896. DOI:10.1073/pnas.0706375104

652 Olesen JM, Bascompte J, Dupont Y, Elberling H, Rasmussen C, Jordano P. 2011.

653 Missing and forbidden links in mutualistic networks. Proceedings of the Royal Society B654 Biological Sciences 278:725-732. DOI: 10.1098/rspb.2010.1371

655 Olito C, Fox JW. 2015. Species traits and abundances predict metrics of plant-pollinator 656 network structure, but not pairwise interactions. Oikos 124:428-436.

657 DOI: 10.1111/oik.01439

658 Ortiz-Pulido R, Diaz SA, Valle-Diaz OI, Fisher A. 2012. Hummingbirds and the plants 659 they visit in Tehuacan-Cuicatlan Biosphere Reserve, Mexico. Revista Mexicana de 660 Biodiversidad 83:152-163.

661 Parker III TA, O’Neill JP. 1976. Introduction to bird-finding in Peru: Part II. The Carpish 662 Pass region of the eastern Andes along the Central Highway. Birding 8: 205-216.

663 Parker III TA, Stotz DF, Fitzpatrick JW. 1996. Ecological and distributional databases.

664 Pages 113-436 in Stotz DF, Fitzpatrick JW, Parker III TA, Moskovits DK, editors.

665 Neotropical birds: ecology and conservation. Chicago: University of Chicago Press.

666 R Core Team 2014. R: A language and environment for statistical computing. - R

667 Foundation for Statistical Computing. http://www.R-project.org/. 
668 Rafferty NE, CaraDonna PJ, Bronstein JL. 2015. Phenological shifts and the fate of 669 mutualisms. Oikos 124:14-21. DOI: 10.1111/oik.01523

670 Ramirez O, Arana M, Bazan E, Ramirez A, Cano A. 2007. Assamblages of two mammal 671 and bird communities in two major ecological units in the high Andean plateau of 672 southern Peru. Ecologia Aplicada 6(1-2):1-15.

673 Ramos-Robles M, Andresen E, Diaz-Castelazo C. 2016. Temporal changes in the 674 structure of a plant-frugivore network are influenced by bird migration and fruit 675 availability. Peerj 4. DOI: 10.7717/peerj.2048

676 Remsen JV, Good DA. 1996. Misuse of data from mist-net captures to assess relative 677 abundance in bird populations. Auk 113:381-398.

678 Rodriguez-Flores Cl, Stiles FG, Arizmendi MC. 2012. Pollination network of a hermit 679 hummingbird community (Thochilidae, Phaetornitidae) and their nectar resources in the 680 Colombian Amazon. Ornitologia Neotropical 23:85-100.

681 Rojas-Nossa SV. 2013. Asociación entre el robo de néctar y las características florales 682 en una comunidad montana de los Andes colombianos. Revista Ecosistemas 683 22(2):107-112. DOI: 10.7818/ECOS.2013.22-2.16

684 Rojas-Nossa SV, Sánchez, JM, Navarro L. 2016, Nectar robbing: a common 685 phenomenon mainly determined by accessibility constraints, nectar volume and density 686 of energy rewards. Oikos. DOI: 10.1111/oik.02685 
687 Sebastian-Gonzalez E, Dalsgaard B, Sandel B, Guimaraes P. 2015. Macroecological 688 trends in nestedness and modularity of seed-dispersal networks: human impact matters 689 Global Ecology and Biogeography 24: 293-303. DOI: 10.1111/geb.12270

690 Sekercioglu CH, Primack RB, Wormworth J. 2012. The effects of climate change on 691 tropical birds. Biological Conservation 148:1-18. DOI:10.1016/j.biocon.2011.10.019

692 Suweis S, Simini F, Banavar J, Maritan A. 2013. Emergence of structural and dynamical 693 properties of ecological mutualistic networks. Nature 500:449-452.

694 DOI:10.1038/nature12438

695 Thébault E, Fontaine C. 2010. Stability of Ecological Communities and the Architecture 696 of Mutualistic and Trophic Networks. Science 329: 853-856. DOI:

697 10.1126/science.1188321

698 Traveset A, Olesen JM, Nogales M, Vargas P, Jaramillo P, Antolin E, Trigo MM, Heleno

699 R. 2015. Bird-flower visitation networks in the Galapagos unveil a widespread

700 interaction release. Nature Communications 6. DOI: 10.1038/ncomms7376

701 |www.nature.com/naturecommunications

702 Trojelsgaard K, Jordano P, Carstensen DW, Olesen JM. 2015. Geographical variation in 703 mutualistic networks: similarity, turnover and partner fidelity. Proceedings. Biological 704 sciences / The Royal Society 282. DOI: 10.1098/rspb.2014.2925

705 Tylianakis JM, Tscharntke T, Lewis OT. 2007. Habitat modification alters the structure 706 of tropical host-parasitoid food webs. Nature 445:202-205. DOI: 10.1038/nature05429 
707 Vazquez DP, Aizen MA. 2004. Asymmetric specialization: A pervasive feature of plant-

708 pollinator interactions. Ecology 85:1251-1257. DOI: 10.1890/03-3112

709 Vázquez DP, Aizen MA. 2006. Community-wide pattern of specialization in Plant-

710 Pollinator interactions revealed by null models. In: Waser NM, Ollerton J, editors. Plant-

711 Pollinator Interactions: From specialization to generalization. Chicago: University of

712 Chicago Press, 200-219.

713 Vazquez DP, Chacoff NP, Cagnolo L. 2009. Evaluating multiple determinants of the

714 structure of plant-animal mutualistic networks. Ecology 90:2039-2046. DOI:10.1890/08$715 \quad 1837.1$

716 Vizentin-Bugoni J, Maruyama PK, Sazima M. 2014. Processes entangling interactions

717 in communities: forbidden links are more important than abundance in a hummingbird-

718 plant network. Proceedings of the Royal Society B-Biological Sciences 281:20132397

719 DOI: $10.1098 / \mathrm{rspb} .2013 .2397$

720 Vizentin-Bugoni J, Maruyama PK, Debastiani VJ, Duarte LD, Dalsgaard B, Sazima M.

721 2016. Influences of sampling effort on detected patterns and structuring processes of a

722 Neotropical plant-hummingbird network. Journal of Animal Ecology 85:262-272.

723 DOI: $10.1111 / 1365-2656.12459$

724 Walther BA, Brieschke H. 2001. Hummingbird-flower relationships in a mid-elevation

725 rainforest near Mindo, Northwestern Ecuador. International Journal of Ornithology

$726 \quad 4: 115-135$.

727 Willmer P. 2011. Pollination and Floral Ecology. Princeton: Princeton University Press. 
728 Winfree R, Williams NM, Dushoff J, Kremen C. 2014. Species abundance, not diet

729 breadth, drives the persistence of the most linked pollinators as plant-pollinator

730 networks disassemble. American Naturalist 183:600-611. DOI: 10.1086/675716

731 Young BE, Franke I, Hernandez PA, Herzog SK, Paniagua L, Tovar C, Valqui T. 2009.

732 Using spatial models to predict areas of endemism and gaps in the protection of

733 Andean slope birds. Auk 126(3):554-565.

734 DOI: http://dx.doi.org/10.1525/auk.2009.08155 


\section{Figure 1}

Pairwise interactions in the bird-flowering plant visitation network in the elfin forest of Unchog (Peruvian Andes).

Each green box represents a plant species; blue boxes are hummingbirds, orange are flowerpiercers. The lines represent the interactions and the thickness of the line reflects the number of interactions. 


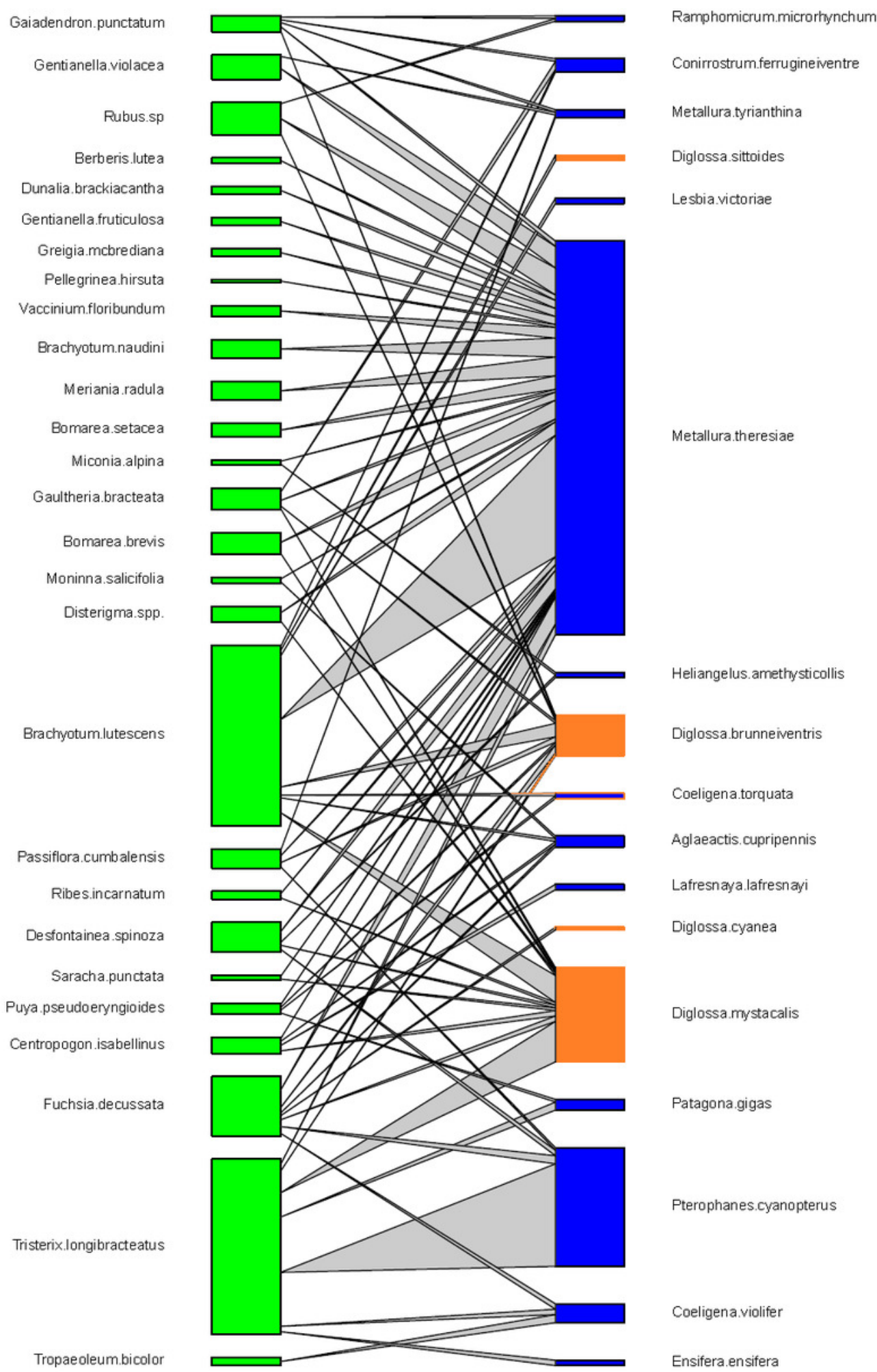




\section{Figure 2 (on next page)}

Comparison of the network metrics produced by probability matrices (mean and $95 \%$ confidence intervals) and the observed network values for the bird-flowering plant network of the elfin forest.

The dashed vertical lines in each graph represents the value for the observed matrix. Matrix codes: $A b=$ Abundance, Phen=Phenology, Mor=Morphology, Null= Null matrix. 

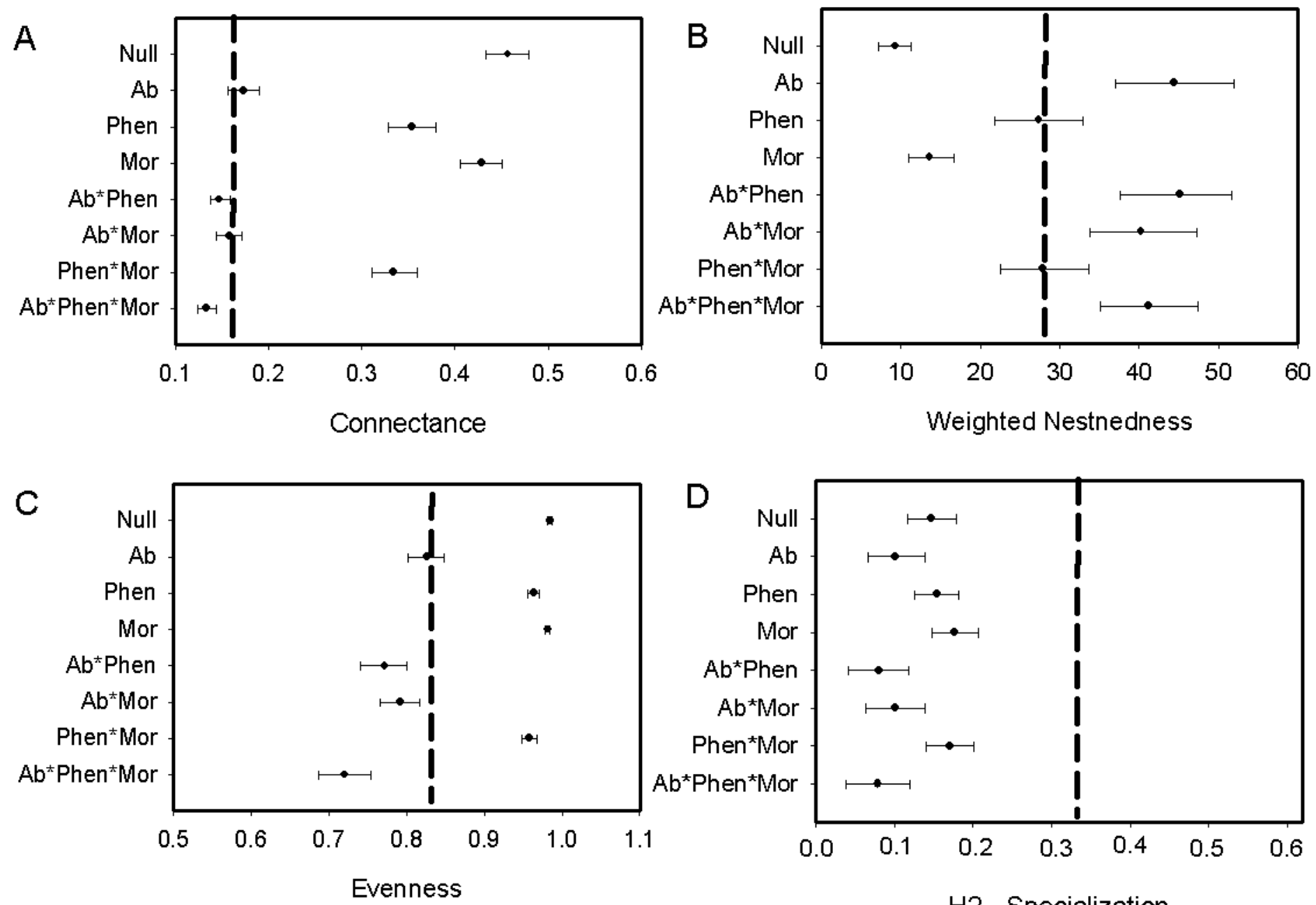

H2 - Specialization
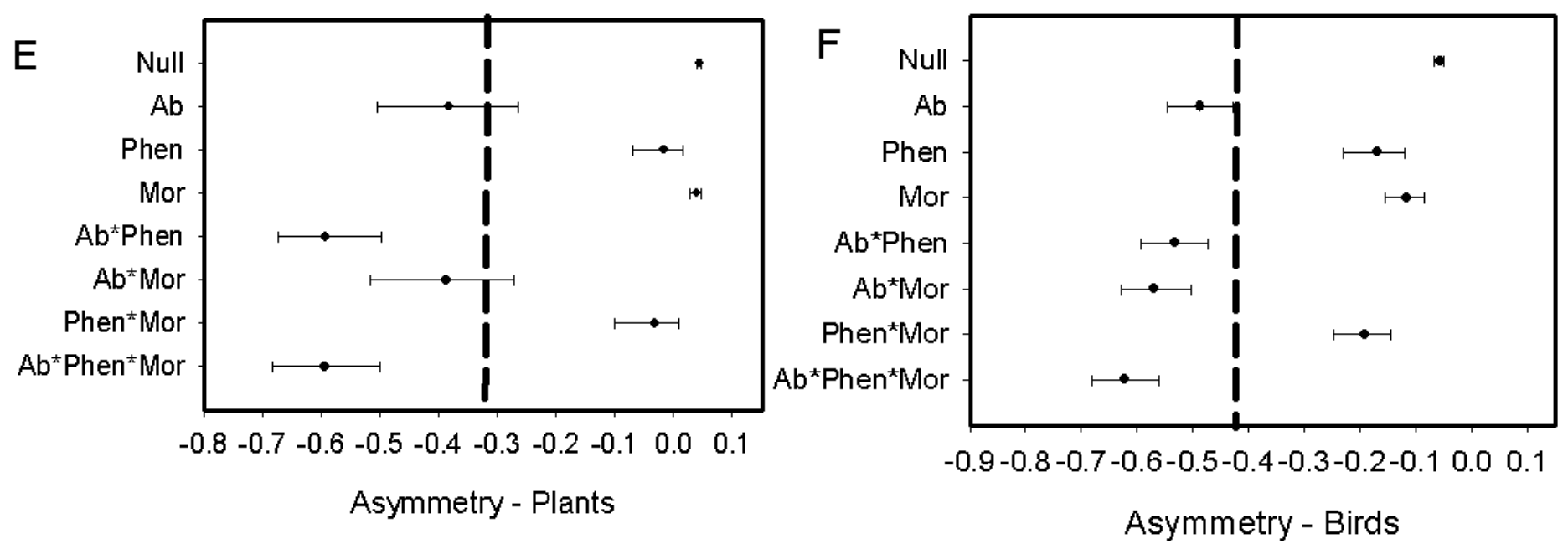


\section{Figure 3}

Comparison of the network metrics produced by probability matrices after removal of interactions involving nectar-robbers

The dashed vertical lines in each graph represents the value for the observed matrix. Matrix codes: $\mathrm{A} b=$ Abundance, Phen=Phenology, Mor=Morphology, Null= Null matrix. 

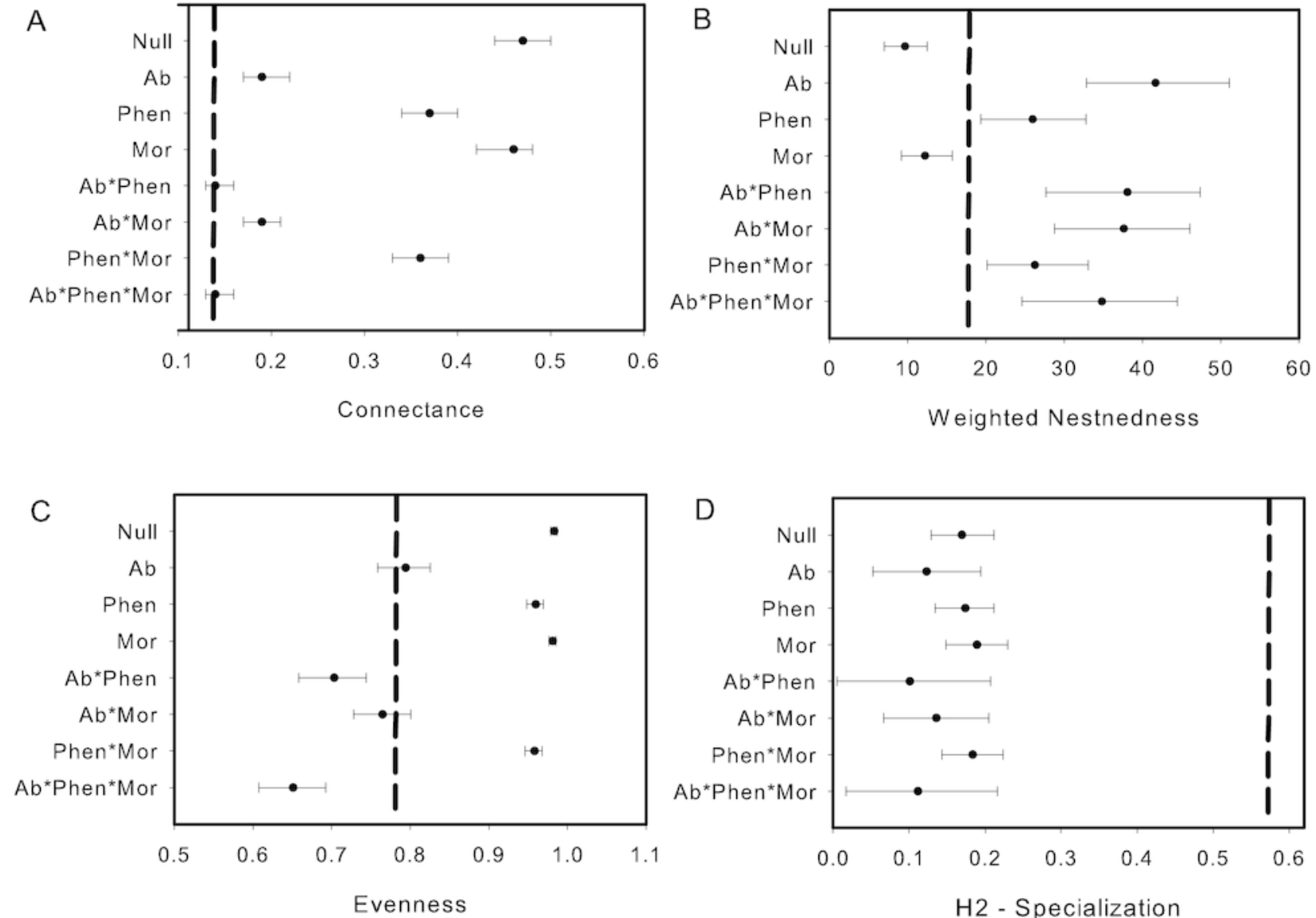

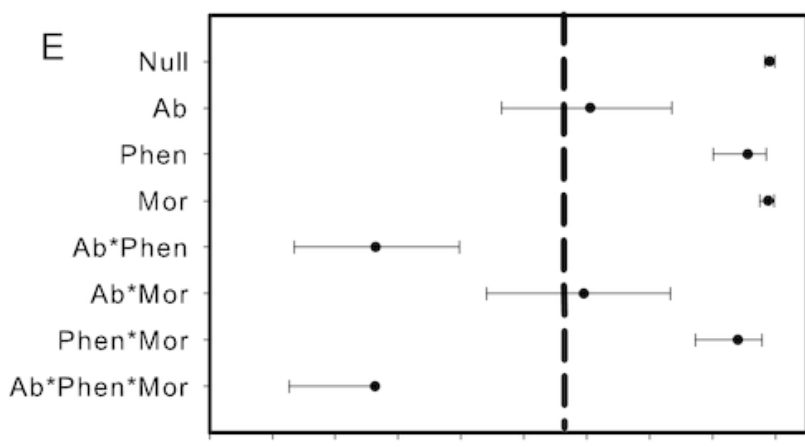

$\begin{array}{llllllllll}-0.8 & -0.7 & -0.6 & -0.5 & -0.4 & -0.3 & -0.2 & -0.1 & 0.0 & 0.1\end{array}$

Asymmetry - Plants

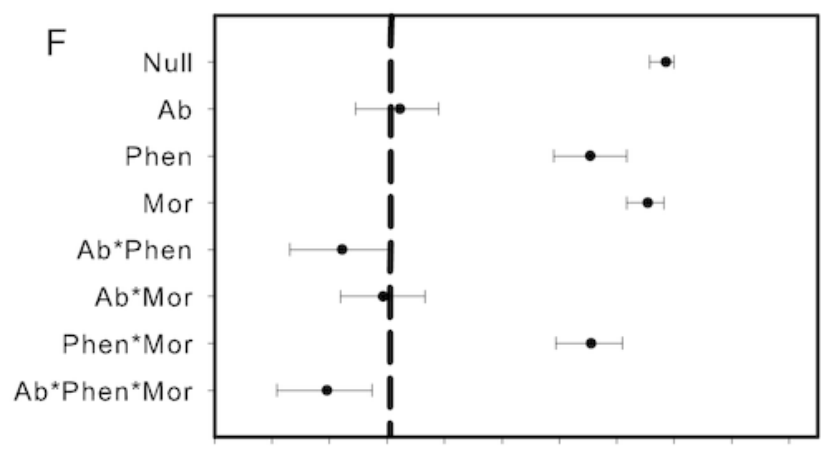

$-0.9-0.8-0.7-0.6-0.5-0.4-0.3-0.2-0.10 .00 .1$

Asymmetry - Birds 


\section{Table $\mathbf{1}$ (on next page)}

Difference of the AIC values between various models predicting observed interaction frequencies and the model with lowest AIC value.

$\mathrm{Ab}=$ Abundance, Phen $=$ Phenology, Mor $=$ Morphology, Null= Null matrix. The visitation network includes all bird species and the pollination network excludes interactions where birds did not visit flowers legitimately. In both matrices, phenology was the best predictor of interaction frequencies. 
1 Table 1. Difference of the AIC values between various models predicting observed

2 interaction frequencies and the model with lowest $A I C$ value. $A b=$ Abundance, Phen=

3 Phenology, Mor= Morphology, Null= Null matrix. The visitation network includes all bird

4 species and the pollination network excludes interactions where birds did not visit

5 flowers legitimately. In both matrices, phenology was the best predictor of interaction

6 frequencies.

7

\begin{tabular}{lrr}
\hline & $\begin{array}{l}\Delta \text { AIC } \\
\text { visitation } \\
\text { network }\end{array}$ & $\begin{array}{l}\Delta \text { AlC } \\
\text { pollination } \\
\text { network }\end{array}$ \\
\hline Phen & 0 & 0 \\
Ab & 428.2 & 180.3 \\
Null & 588.6 & 433.4 \\
Ab*Phen & 660.1 & 387.0 \\
Phen*Mor & 1262.9 & 122.9 \\
Ab*Mor & 1846.8 & 365.0 \\
Mor & 1912.1 & 575.9 \\
Ab*Phen*Mor & 2067.4 & 563.7 \\
\hline
\end{tabular}

8

9 